\title{
Caracterización Morfológica, Génica y Protéica en la Diferenciación de Células Madre Embrionarias de Ratón a Células Pancreáticas Tempranas
}

\author{
Morphological, Genetic and Protein Characterization in the \\ Differentiation of Embryonic Stem Cells to Early Pancreatic Cells
}

Vázquez-Zapién, G. J.*; Sánchez Monroy, V.*****; Chirino López, Y. I.********** \& Mata-Miranda, M. M.****

VÁZQUEZ-ZAPIÉN, G. J.; SÁNCHEZ MONROY, V.; CHIRINO LÓPEZ, Y. I. \& MATA-MIRANDA, M. M. Caracterización morfológica, génica y protéica en la diferenciación de células madre embrionarias de ratón a células pancreáticas tempranas. Int. J. Morphol., 31(4):1421-1429, 2013.

RESUMEN: Debido al auge de la medicina regenerativa, las Células Madre (SC) representan una fuente de reemplazo celular para cualquier tejido, decidiendo emprender este trabajo de investigación con el objetivo de diferenciar células madre embrionarias de ratón (mESC) a células pancreáticas tempranas, realizando su caracterización génica y morfológica. Primeramente se cultivaron y arrestaron en su ciclo celular fibroblastos embrionarios de ratón (MEF) con mitomicina, posteriormente se expandieron las mESC y se sometieron a un protocolo de diferenciación de 21 días hacía células pancreáticas tempranas, evaluándose durante la diferenciación su morfología y expresión relativa de los genes sox-17, $p d x-1$, ins-1 e ins-2, determinando además la producción de las proteínas insulina y glucagón mediante inmunocitoquímica y citometría de flujo. Se obtuvieron cuerpos embrionarios (EBs) a partir de mESC, con características morfológicas diferentes de acuerdo a su diferenciación, los cuales expresaron genes de la línea germinal endodérmica (sox-17 y $p d x-1)$ a los días 0,11 y 17 de diferenciación, gen inductor del desarrollo embrionario pancreático ( $p d x-1)$ al día 11 de diferenciación y, genes de expresión pancreática (ins-1 e ins-2) a los días 17 y 21 de diferenciación. Finalmente se detectó la producción de proteínas insulina y glucagón en los EBs al día 21 de diferenciación. Se logró diferenciar mESC. El análisis morfológico evidenció cúmulos celulares tridimensionales correspondientes a EBs. Con el análisis de los patrones de expresión génica, se distinguieron inicialmente células con características genéticas de endodermo y posteriormente a partir del día 17 células pancreáticas tempranas, las cuales al día 21 de diferenciación expresaron las proteínas insulina y glucagón. Los resultados anteriores sugieren la necesidad de continuar protocolos de diferenciación para determinar el comportamiento de ESC sometidas a diferenciación y su posible uso terapéutico al implantar células diferenciadas y especializadas en modelos animales.

PALABRAS CLAVE: Células madre; Stem cell; Diferenciación de células madre; Células diferenciadas; Cuerpos embrionarios; Células productoras de insulina.

\section{INTRODUCCIÓN}

De acuerdo a la Asociación Americana de Diabetes (Expert Committee on the Diagnosis and Classification of Diabetes Mellitus, 2003), la diabetes Mellitus (DM) es un grupo de trastornos metabólicos caracterizados por la hiperglucemia resultante de los defectos de la secreción o la acción de la insulina, o ambas. La DM1 se caracteriza por la deficiencia de células $ß$ endocrinas en los islotes pancreáticos (Ku et al., 2004). Desde el descubrimiento de la insulina hace más de 80 años, el tratamiento de la DM no ha cambiado y sigue girando alrededor de fármacos hipoglucemiantes y terapia de reemplazo con insulina. El trasplante de los islotes pancreáticos es una alternativa, pero su uso está restringido a los órganos donados, al rechazo inmune y la necesidad de inmunosupresores. Es por eso que se han propuesto alternativas para la obtención de células $B$ a partir de células madre embrionarias (ESC) (Baetge, 2008; Wong, 2011).

Una SC, es capaz de dividirse indefinidamente y diferenciarse en distintos tipos de células especializadas, no sólo morfológicamente sino también de forma funcional

* Subsección de Investigación, Escuela Médico Militar, Universidad del Ejército y Fuerza Aérea, México DF, México.

** Laboratorio Multidisciplinario de Investigación, Escuela Militar de Graduados de Sanidad, Universidad del Ejército y Fuerza Aérea, México DF, México.

**** Programa Institucional de Biomedicina Molecular ENMyH; Instituto Politécnico Nacional, México DF, México.

***** Subsección de Biología Celular y Tisular, Escuela Médico Militar, Universidad del Ejército y Fuerza Aérea, México DF, México.

****** Unidad de Biomedicina, Facultad de Estudios Superiores Iztacala, Universidad Autónoma de México, México. 
(Prósper et al., 2006). El microambiente de las SC llamado nicho, es la suma de todos los factores celulares y moleculares que regulan e interactúan con las mismas células (Walker et al., 2009), mismo que permitirá que una SC se diferencie a una célula especializada o se conserve como SC (Spradling et al., 2001; Giraldo et al., 2003). Es por esto, que con diferentes medios de cultivo se puede inducir la diferenciación de una ESC a una célula especializada, como lo han hecho diversos autores entre ellos Ku et al. en el 2004 y Chen et al. en el 2011, quienes han realizado trabajos en los que diferenciaron ESC de ratón a células pancreáticas in vitro, formando primeramente EBs y, posteriormente indujeron la diferenciación a células productoras de insulina, adicionado a los medios de cultivo nicotinamida, exedina y activina bB (Ku et al.; Chen et al., 2011).

En el desarrollo embrionario del páncreas de ratón, uno de los primeros factores de transcripción que se expresan es el "SRY-box que contiene el gen 17" (sox-17), el cual es un determinante endodérmico y participa en la organogénesis, formando el tubo digestivo primitivo que originará el tracto digestivo, hígado, páncreas y algunos otros órganos viscerales. El estudio de Kanai-Azuma et al. (2002) demostró que embriones de ratón mutantes sox17-/- tuvieron deficiencias en la formación del endodermo definitivo. Se ha citado también que sox-17 inhibe la transcripción de muchos genes normalmente expresado en las SC y es requerido para antagonizar apropiadamente la expresión de sox-2, nanog y oct-4 (Niakan et al., 2010).

Otro de los genes esenciales para el desarrollo embrionario del páncreas, es Homebox 1 pancreático y duodenal $(p d x-1)$ (Hui \& Perfettu, 2002), el cual juega un papel pleiotrópico, ya que es expresado en precursores de los compartimentos tanto endocrinos como exocrinos del páncreas y, además de participar en la diferenciación de las células $\beta$, también mantiene el funcionamiento y regulación de las células B maduras (Kaneto et al., 2007; Akincin et al., 2012).

En las células pancreáticas de ratas y ratones se expresan dos genes de insulina no alélicos (genes I y II) (Fomina-Yadlin et al., 2012). Ambos genes se expresan en múltiples sitios durante el desarrollo del ratón. Las neuronas expresan únicamente insulina II, el páncreas expresa ambas insulina I (ins-1) y II (ins-2), el hígado fetal y el saco vitelino expresa predominantemente insulina II (Ku et al.).

En este estudio, se sometieron mESC a un protocolo de diferenciación de 21 días utilizando factores e inductores pancreáticos, obteniendo cuerpos embrionarios (EBs) conformados por células pancreáticas tempranas a los cuales se les caracterizó morfológica y genéticamente, además de evidenciar la presencia de las proteínas de insulina y glucagón.

\section{MATERIAL Y MÉTODO}

Expansión y arresto celular de fibroblastos embrionarios de ratón. Los fibroblastos embrionarios de ratón (MEF), de la línea celular STO (S, SIM; T, 6-resistente a la tioguanina; $\mathrm{O}$, resistente a la ouabaina), se sembraron en un medio Eagle modificado por Dulbecco (DMEM) (ATCC cat: 30-2002), suplementado con 15\% de suero fetal bovino (FBS) (ATCC cat: $30-2020$ ) y $1 \%$ de Penicilina 10,000 UI/ml/ Estreptomicina 10,000 mg/ml (Invitrogen, cat: 15140). Una vez que los MEF alcanzaban una confluencia del $80 \%$, se procedió a su arresto celular, para lo cual se despegaron con $1 \mathrm{ml}$ de tripsina / 0.53 EDTA (ATCC cat: 30-2101) y se sembraron a una densi-

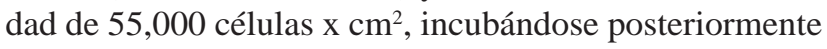
con mitomicina a razón de $10 \mathrm{ml} / \mathrm{ml}$ de DMEM durante 4 horas y finalmente se utilizaron como células alimentadoras para las mESC.

Expansión y diferenciación de las ESC de ratón. Las mESC (ATCC cat: SCRR-2010) se sembraron a una densidad de 50,000 células $\mathrm{x} \mathrm{\textrm {cm } ^ { 2 }}$ sobre una monocapa de MEF previamente arrestados para mantenerlas en estado indiferenciado, para lo que se suplementó el medio basal de mESC (ATCC cat: SCRR-2010) con 15\% FBS, 2- 3 mercaptoetanol al 0,1 mM (Invitrogen cat: 21985023) y factor inhibidor de leucemia (LIF) a razón de $1000 \mathrm{U} / \mathrm{ml}$ (Chemicon cat: ESG1107), incubándose a $37^{\circ} \mathrm{C}$ y $5 \% \mathrm{CO}_{2}$. Posteriormente para la obtención de EBs, se sembraron las mESC a una densidad de 200,000 células x ml, y se diferenciaron siguiendo el protocolo que se representa en la Figura 1 y que a continuación se describe: Medios 1 y 2 de diferenciación utilizados los días 0 y 2 de diferenciación respectivamente, los cuales contienen medio Iscove Dulbbecco modificado (IMDM) (Sigma cat: 51471C), monotioglicerol (MMTG) (Sigma cat: M4165), ácido ascórbico (AA) (Sigma cat: A5960) suero fetal de ternera (FCS) (Promocell cat: C-37350); medio de diferenciación 3 utilizado a partir del día 6 de diferenciación, el cual contiene suero de reemplazo (SR) (Invitrogen cat: 10828010), factor de crecimiento de fibroblastos purificados recombinantes humanos (FGF2) (Sigma cat: F0291) y Dulbecco's Modified Eagle Medium: Nutrient Mixture F12 (DMEM/F12) (Invitrogen cat: 11320-033). Para el reemplazo de medios, los EB fueron enjuagados previamente con IMDM y albúmina sérica bovina al $0.1 \%$ (Sigma cat: A2153). Al día 13 los EB se mantuvieron en medio 3 complementado con nicotinamida al $10 \mathrm{mM}$ (Sigma, cat: N0636), exedina-4 al $0.1 \mathrm{nM}$ (American Peptide Company, cat: 46-3-12) y activina bB humana recombinante a razón de $10 \mathrm{ng} / \mathrm{ml}$ (Sigma, cat: A1729) hasta el final del protocolo para su análisis. 


\begin{tabular}{lll}
\hline \multicolumn{1}{c}{ MEDIO DE } & \multicolumn{1}{c}{ MEDIO DE } & \multicolumn{1}{c}{ MEDIO DE } \\
DIFERENCIACIÓN 1 & DIFERENCIACIÓN 2 & DIFERENCIACIÓN 3 \\
\multicolumn{1}{c}{ (MD1) } & \multicolumn{1}{c}{ (MD2) } & \multicolumn{1}{c}{ (MD3) } \\
\hline IMDM & IMDM & DMEM $/ \mathrm{F} 12$ \\
A.A. $50 \mu \mathrm{g} / \mathrm{ml}$ & A.A. $50 \mu \mathrm{m} / \mathrm{ml}$ & SR $15 \%$ \\
MMTG $6 \times 10^{3} \mathrm{M}$ & MMTG $6 \times 10^{4} \mathrm{M}$ & FGF2 $10 \mathrm{ng} / \mathrm{ml}$ \\
FCS $15 \%$ & FCS $15 \%$ & \\
\hline
\end{tabular}

A

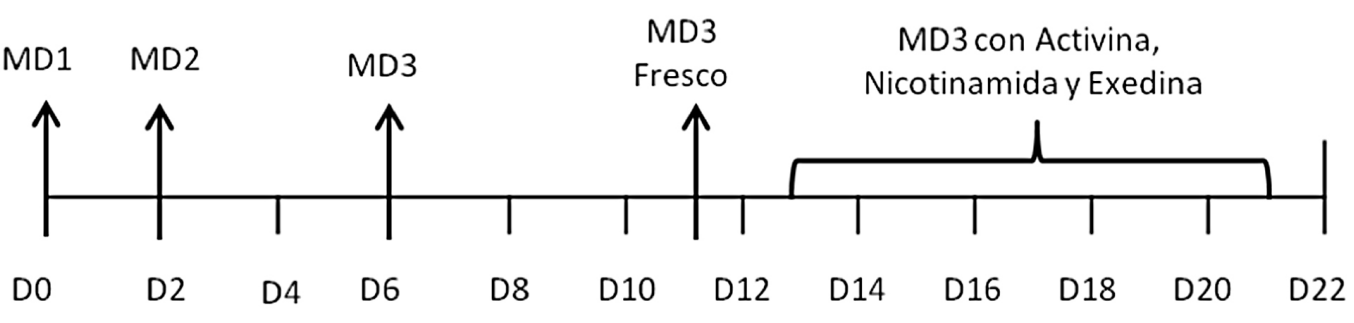

Fig. 1. Proceso de diferenciación de mESC a células pancreáticas tempranas en 21 días. A. Medios de diferenciación utilizados y B. cambios de medios en el transcurso de la diferenciación.

Descripción de la morfología de las ESC y de las células diferenciadas. Los cambios morfológicos durante el proceso de diferenciación fueron seguidos con el uso de un microscopio axioskop 2 plus de la marca Carl Zeiss. Para determinar el tamaño celular, se obtuvieron las áreas celulares en pixeles², por lo que se utilizó como patrón de medida un eritrocito para la conversión a $\mu \mathrm{m}^{2}$. A los $0,11,17$ y 21 días de cultivo en diferenciación, se midieron 100 células en cada uno de los cultivos y se obtuvo el promedio de las áreas de las células.

Ensayos de expresión relativa por RT-PCR en tiempo real (RT Q-PCR). Se realizaron tres replicas biológicas de los cultivos a los $0,11,17$ y 21 días de cultivo en diferenciación. Se aisló el RNA y se trató con DNasa (RQ1 RNaseFree DNase Promega) para evitar la contaminación por DNA genómico, se sintetizó cDNA utilizando el kit first strand cDNA (invitrogen), de acuerdo a las instrucciones del fabricante y, de cada una de las muestras obtenidas de cDNA se realizó la RT Q-PCR. Todas las RT Q-PCR fueron analizadas por triplicado.

Se utilizó el programa Primer Express 3.0 desarrollado por Applied Biosystems para el diseño de los oligonucleótidos incluido el gen endógeno (Tabla I). La RT Q-PCR se realizó en el equipo ABI PRISM 7000 Sequence Detection System (Applied Biosystems), utilizando SYBR Green como sistema de detección y el kit SYBR Green PCR Master Mix (Applied Biosystem). La cuantificación relativa se calculó utilizando el método DDCT, el cual usa la fórmula aritmética 2- DDCT (Livak \& Schmittgen, 2001). Para validar el método 2- DDCT, se verificó la eficiencia de la amplificación de los genes en estudio y del endógeno ppia, siendo muy similares. La diferencia de la significancia estadística en la expresión de los genes entre las células de los diferentes días de diferenciación, se analizaron utilizando la prueba de T pareada, Tukey y Anova.

Tabla I. Oligonucleótidos diseñados en el programa primer express 3.0 de Applied Biosystems, que se utilizaron para caracterizar la expresión génica de las células pancreáticas diferenciadas a partir de mESC.

\begin{tabular}{lcc}
\hline Gen & Iniciador sentido 5'-3' & Iniciador antisentido 5-3' \\
\hline ppia & CCAGGATTCATGTGCCAGG & GCCATCCAGCCATTCAGTCT \\
so $x-17$ & CTTCCCTACCAGGGACACGA & ACTGCTTCTGGCCCTCAGGT \\
pdx-1 & GGTGCTTACACAGCGGAACC & CGGTCAAGTTCAACATCACTGC \\
$i n s-1$ & GCTCTTCCTCTGGGAGTCCC & AAGGTCTGAAGGTCACCTGCTC \\
$i n s-2$ & GCTCTTCCTCTGGGAGTCCC & AAGGTCTGAAGGTCACCTGCTC \\
\hline
\end{tabular}


Inmunocitoquímica. Al inicio y al final de la diferenciación, los EBs se fijaron con paraformaldehído (Sigma, cat: P6148) $4 \%$ y ácido pícrico (Sigma, cat: 197378) 0.15\%, posteriormente se permeabilizó su membrana con Triton X100 al $0.1 \%$ durante 5 minutos, se lavaron con PBS y en seguida se adicionaron $100 \mu \mathrm{l}$ del suero con proteína bloqueadora durante 10 minutos. Enseguida se realizó el marcaje de los EBs con los anticuerpos (Ab) primarios Guinea Pig antiswine insulin (1:20, Dako cat: A0564) y rabbit antihuman glucagón (1:50, Dako cat: A0565), dejándose incubar por 60 minutos y lavandose con PBS. Posteriormente los EBs se marcaron con los $\mathrm{Ab}$ secundarios de cy3-conjugated donkey anti-guinea pig (1:200, Jackson cat: 706-166-148) y cy2-conjugates donkey anti rabbit (1:100, Jackson cat: 711096-152) incubándose durante 60 minutos en oscuridad y posteriormente se lavaron con PBS. Finalmente se colocó glicerol al 10\% y cubreobjetos para su análisis en el microscopio de fluorescencia OLYMPUS BX4.

Análisis por citometría de flujo. Al inicio y al final de la diferenciación se obtuvo una suspensión celular, misma que se centrifugó a 1,200 rpm por 10 minutos, se decantó el sobrenadante y se le agregó el Ab primario para insulina (1:100), incubándose 30 minutos, se lavaron con PBS y se centrifugaron nuevamente durante 10 minutos, se decantó el sobrenadante y se les agregaron su respectivo Ab secundario (1:250) dejándolo incubar durante 30 minutos, posteriormente las muestras fueron lavadas nuevamente con PBS, para finalmente ser sometidas a su análisis en un citómetro FACSCalibur (Becton, Dickin).

\section{RESULTADOS}

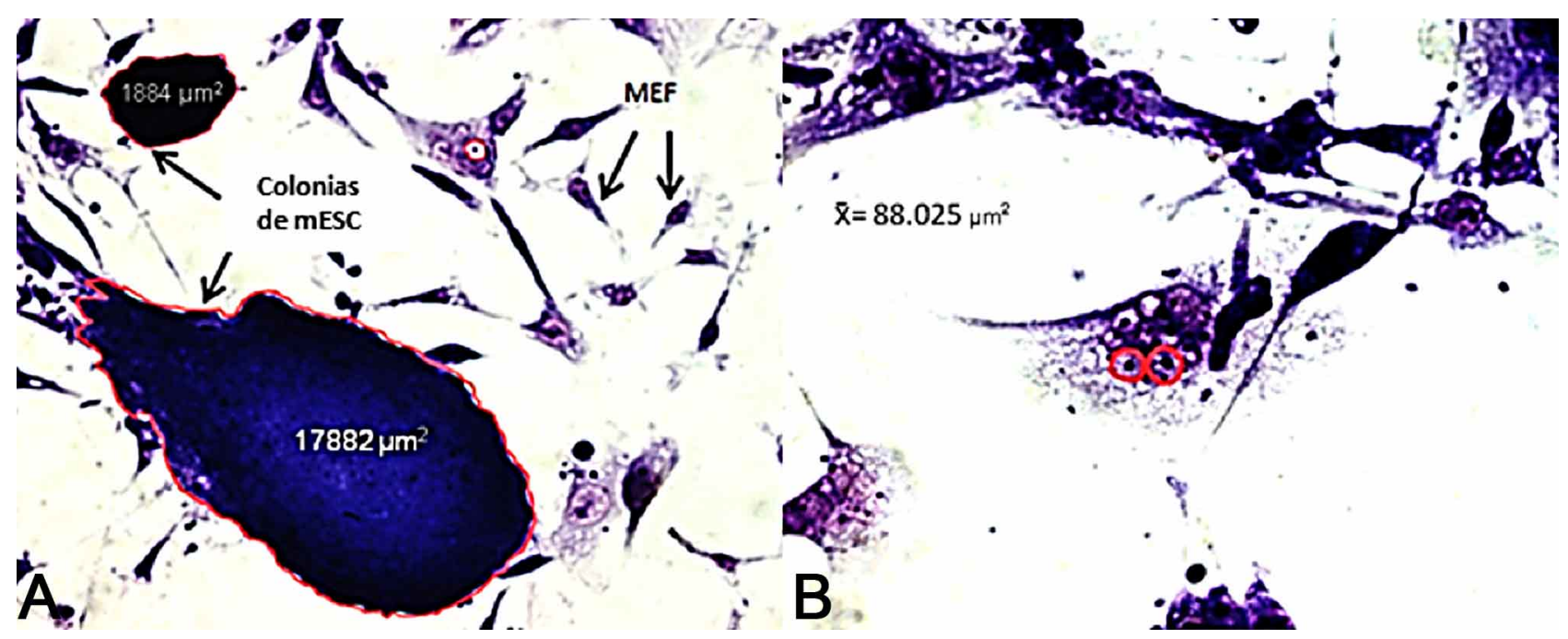

Fig. 2. mESC en tinción de Giemsa (40X). A. Colonias de mESC sobre una monocapa de MEF; área celular de las colonias en rojo. B. Colonia de mESC en formación, área de las células en rojo. pancreáticas tempranas, realizandosu caracterización génica, morfológica y proteica. Primero seguimos los cambios morfológicos antes y durante el proceso de diferenciación y observamos que las mESC en expansión crecieron en colonias con tamaños heterogéneos desde $1884 \mu \mathrm{m}^{2}$ hasta 17 $882 \mu \mathrm{m}^{2}$, además de ser asincrónicas y clonogénicas, mientras que el promedio del área de una mESC fue de 88.025 $\mu \mathrm{m}^{2}$ (Fig. 2). Al someter las mESC al protocolo de diferenciación se formaron EBs conformados por células pancreáticas tempranas diferenciadas. En los primeros 4 días de diferenciación se observaron grupos de 2 a 4 células que conformarían los EBs. Posteriormente al día 11 de diferenciación se observaron células dispersas con un área celular promedio de $80.102 \mu \mathrm{m}^{2}$ (Fig. 3A), las cuales al aumentar la población para el día 17 conformaron nítidamente los EBs pero sin definir cada una de las células que los conformaban (Fig. 3B) debido a la densidad celular. Sin embargo, en otros campos en la periferia de los EBs, se distinguieron células aisladas de tamaños similares a los del día 11. Al día 17 de diferenciación (Fig. 3C), los EBs se observaron bien conformados y densos, tomando un aspecto tridimensional. Para el día 21 de diferenciación los EBs presentaron mayor densidad, pero el área de las células que los conformaban no se modificó (Fig. 3D), reiterando que el área celular de cada una de las células que integraron los EBs en los diferentes días de diferenciación no sufrieron una modificación significativa en su tamaño (Figs. 2 y 3 ).

Los cambios de expresión para los genes sox-17, $p d x$ 1, ins-1 e ins-2 durante el curso de la diferenciación, se re(marcador de la línea germinal endodérmica) se detectó al sumen en la Figura 4, donde se aprecia que el gen sox-17 


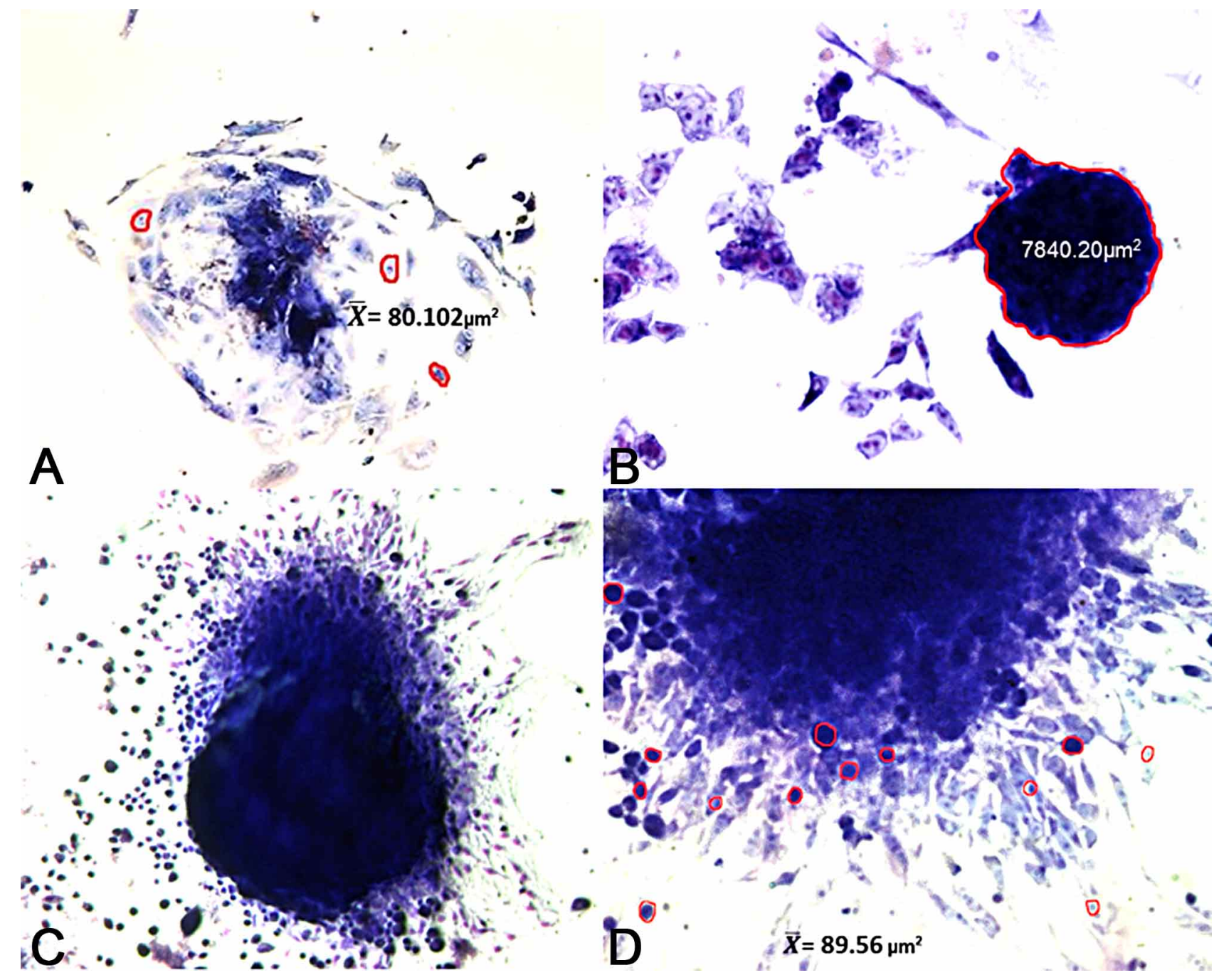

Fig. 3. EB en tinción de Giemsa A. Cuerpo Embrionario (40X) día 11 de diferenciación, área celular en rojo. B. Cuerpo Embrionario (40X) día 17 de diferenciación, área del EB en rojo. C. Cuerpo Embrionario (5X) día 17 de diferenciación. D. Cuerpo Embrionario (40X) día 21 de diferenciación, área celular en rojo.

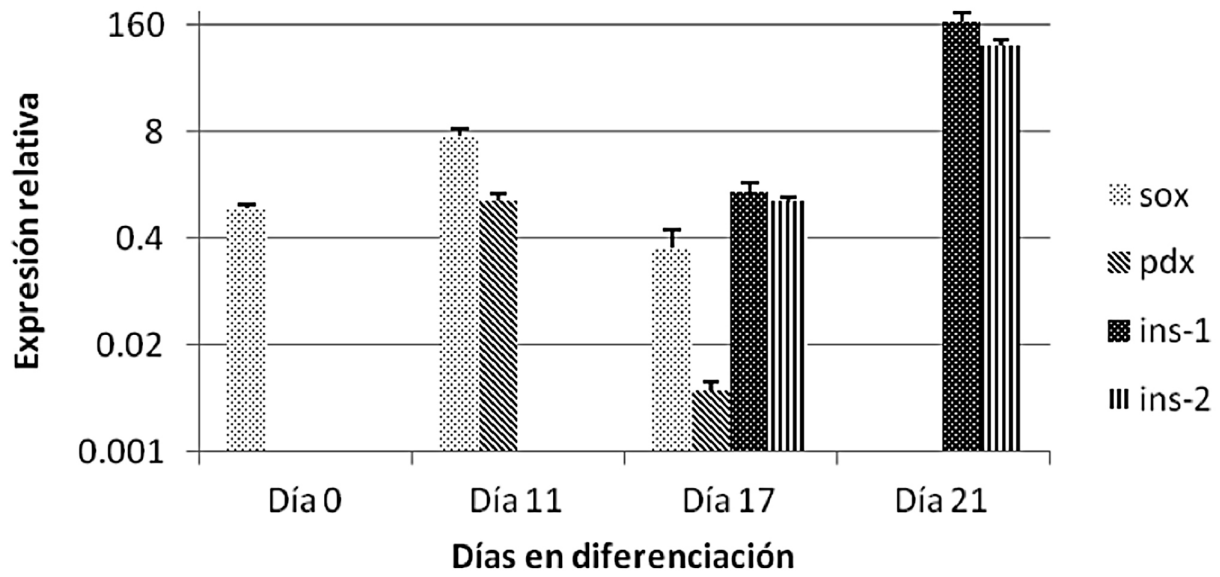

Fig. 4. La figura representa la detección y niveles de expresión relativa de los genes durante el curso de la diferenciación. En los primeros días hubo expresión de los genes endodérmicos, mientras que en los días finales de la diferenciación se expresaron los genes de la insulina I y II. 
día 0 e incrementó su expresión 7 veces más después de 11 días de diferenciación, disminuyendo posteriormente en el día 17 , llegando hasta valores 0,2 veces respecto al día cero. El gen $p d x-l$ (gen necesario durante el desarrollo del páncreas, que posteriormente se restringe a las células $\beta$ maduras del páncreas) solo se detectó los días 11 y 17, observando una marcada disminución de expresión de 10 veces menos al día 17 respecto al día 11 de diferenciación. Finalmente los genes ins-1 e ins-2 se detectaron solo los días 17 y 21 de diferenciación, mostrando sobreexpresión de 178 y 89 veces más al día 21 respecto al día 17 de diferenciación.

En cuanto a la detección de insulina y glucagón me- diante inmunocitoquímica, se observó que las colonias de mESC no expresaban estas proteínas, en contraste a todos los EBs al día 21de diferenciación en los cuales se evidenció la expresión de dichas proteínas (Fig. 5). Los análisis de citometría de flujo evidenciaron un mayor porcentaje $(15,4 \%)$ de células positivas para insulina en comparación con las mESC (2\%). Así mismo, estos ensayos apoyaron las evidencias previas examinadas con citometría de flujo, en las cuales la superficie celular tanto de las mESC como de las células diferenciadas, no aumenta conforme se diferencian a un linaje específico, a diferencia de la complejidad celular la cual aumentó al diferenciar las mESC a células pancreáticas tempranas.

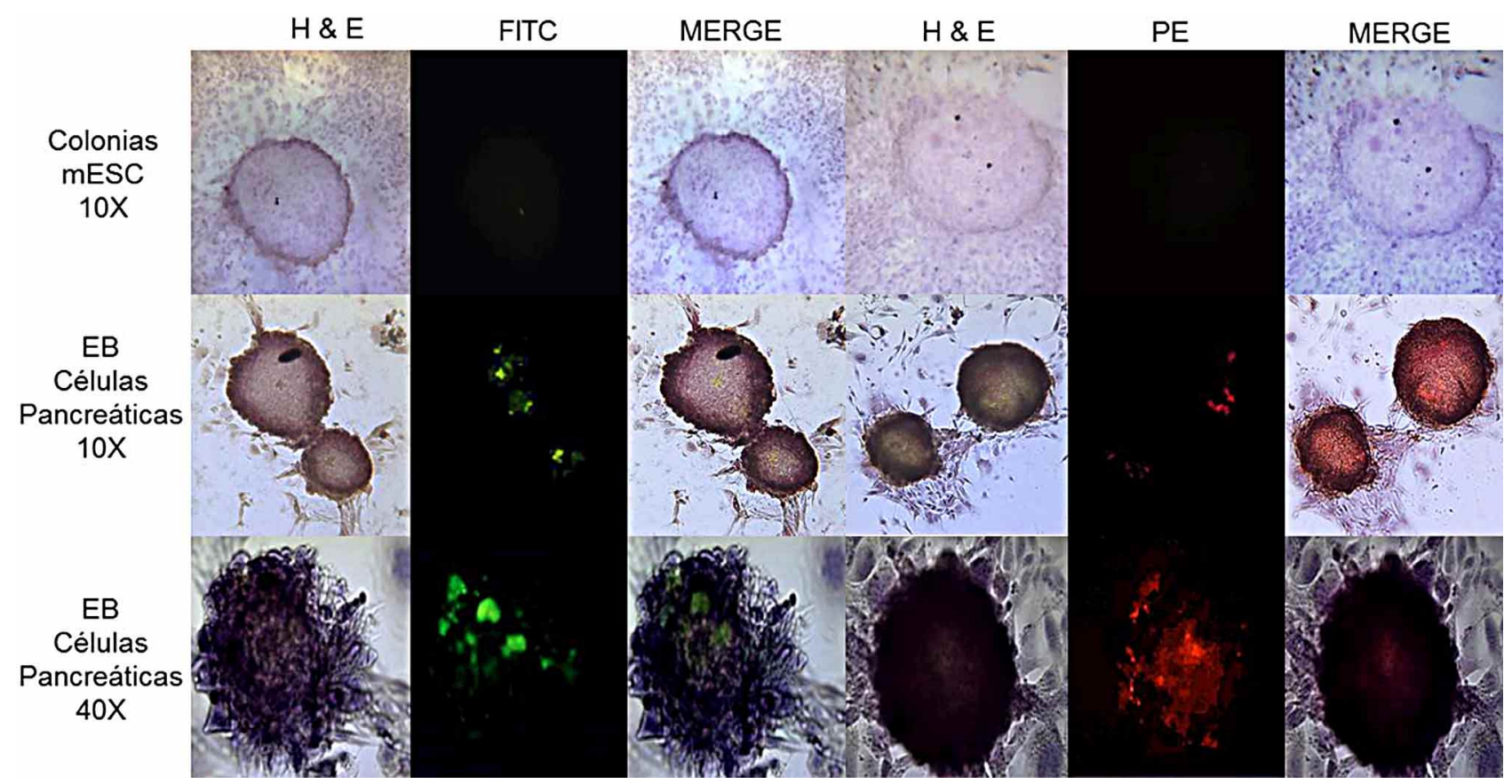

Fig. 5. Imagen representativa de la expresión de insulina y glucagón detectada mediante inmunocitoquímica en los EBs conformados por células pancreáticas tempranas diferenciadas a partir de células madre embrionarias (mESC). Fluoresceína contra insulina (FITC), Ficoeritrina (PE) contra glucagón, tinción Hematoxilina-Eosina (H \& E), n=3.

\section{DISCUSIÓN}

La investigación con células madre y las características que se han observado, han abierto diversos campos de investigación en todo el mundo con la finalidad de poder obtener una fuente de regeneración y de reemplazo de células y tejidos dañados por enfermedades o degeneración biológica.

Recientes investigaciones se han dirigido a la generación de células productoras de insulina utilizando sistemas de cultivo a partir de ESC y EBs para proveer células trasplantables y útiles como herramienta terapéutica en enfermedades como la DM, aunque en estudios previos estos sistemas de cultivo con ESC no han mostrado la caracterización morfológica ni el seguimiento microscópico en las diferentes etapas de diferenciación de manera que sea útil como patrón para trabajos posteriores en la diferenciación de ESC. Nosotros teñimos los cultivos de las ESC sometidas al protocolo de diferenciación y las analizamos mediante microscopía directa en diferentes tiempos del proceso de diferenciación. 
Se ha reportado el uso de mESC y su expansión sobre MEF (Evans \& Kaufman, 1981), obteniéndose en este trabajo resultados semejantes, al observar el crecimiento de colonias, así como la disociación enzimática que sufren estas colonias para que posteriormente a partir de una sola mESC se vuelva a generar una colonia demostrando la clonogenicidad de esta línea celular.

La diferenciación in vitro de las mESC se hizo removiendo el medio de cultivo que contenía LIF, el cual mantiene en estado indiferenciado a las $\mathrm{mESC}$ y, posteriormente se aplicaron los estímulos necesarios para su diferenciación en las tres líneas germinales. Algunos autores como Ku et al. y Chen et al. han reportado el uso de factores de diferenciación y especificación para la obtención células $\beta$ productoras de insulina y glucagón a partir de ESC, tales como nicotinamida, exedina-4 y activina $\mathrm{B}$, estableciendo tiempos específicos durante el protocolo de diferenciación. En este protocolo de diferenciación se obtuvieron EBs conformados por células pancreáticas tempranas diferenciadas que expresaron insulina y glucagón, coincidiendo estos resultados con las investigaciones de Ku et al. y otros autores como Leahy et al. (1999), quienes establecen que cuando las mESC se inducen a un protocolo de diferenciación y en la ausencia de factores anti-diferenciación, se obtienen agregados celulares tridimensionales llamados EBs.

Similar a las características morfológicas descritas por Itskovitz-Eldor et al. (2000), en este trabajo pudimos notar que al principio de la diferenciación, los EBs son paquetes de células densas que están rodeadas por células parecidas a las endodérmicas y que éstos posteriormente son cavitados, además de que el cuerpo embrionario cístico es el resultado en una diferenciación espontánea, enfatizando que en esta investigación no obtuvimos EBs maduros, debido a que la diferenciación se dirigió hacia células pancreáticas. En contraste con otros autores como Ku et al., quien inició la diferenciación sembrando las mESC a una densidad celular de 5,000 células/ml, nosotros iniciamos la diferenciación sembrando las células a 200,000 células/ml, debido a que sembrando las células a una densidad más baja las células sufren apoptosis, basándonos en lo que manifiestan Vog \& Jones (2010): "Las señales del medio ambiente son transmitidas a las células madre por lo nichos, los cuales consisten en la matriz extracelular, el contacto celular directo y los factores solubles que son secretados o concentrados localmente".

De acuerdo al patrón de expresión de sox-17, consideramos que una vez que las mESC se diferencian en una célula específica, en este caso células pancreáticas tempranas, sox-17 deja de expresarse (aproximadamente después del día 17, debido a que ya no las detectamos en el día 21 de diferenciación), es decir, dejan de ser endodermo para conformar células pancreáticas, coincidiendo con los trabajos con células madre hematopoyéticas (HSC) de Jang \& Sharkis (2007). Las HSC fetales expresan sox-17, pero en neonatos la expresión disminuye gradualmente hasta que deja de expresarse al día 8 del nacimiento (Jang \& Sharkis). En cuanto a la expresión de $p d x-1$, como ya se ha citado con anterioridad, es un factor de transcripción esencial para el desarrollo del páncreas y para el mantenimiento de la función de las células b maduras (Kaneto et al.; Akincin et al.), por lo que al expresarse este gen pudimos confirmar que la ruta de diferenciación era correcta, pero al dejarse de expresar este gen intuimos que las células que obtuvimos no son células maduras, y por eso nos referimos a ellas como células pancreáticas tempranas, basándonos también en lo que cita Gu et al. (2002): "la expresión de $p d x-1$ se mantiene en las células precursoras durante el desarrollo del páncreas, pero subsecuentemente se restringe a las células $\beta$ maduras".

Finalmente se detectó la expresión de ins-1 e ins-2, como ya se ha citado previamente, los ratones expresan dos genes de insulina no alélicos (genes I y II) (Fomina-Yadlin et al.). Ambos genes se expresan en múltiples sitios durante el desarrollo del ratón. Las neuronas expresan únicamente insulina II, el páncreas expresa ambas insulina I y II, el hígado fetal y el saco vitelino expresa predominantemente insulina II (Ku et al.) y dado que en el páncreas se expresan los dos genes de la insulina, en este trabajo se detectó la expresión de ambos genes. En los estudios realizados por Deltour et al. (1993), en embriones a los días 9.5 y 10.5 hubo menos mRNA de proinsulina II que I, al día 11.5 la diferencia fue menor, y empezando el día 12,5, se invirtió la proporción, es decir, hubo más mRNA de proinsulina II que proinsulina I, como en el páncreas adulto $\mathrm{y}$, de acuerdo a las observaciones realizadas en este trabajo, la expresión de ins- 1 al día 17 de diferenciación fue ligeramente mayor que ins-2, pero al día 21 de diferenciación la diferencia fue aún mayor, lo que nos da otra base más de acuerdo a Deltour et al. para afirmar que las células que se diferenciaron son células pancreáticas tempranas, coincidiendo además nuestros resultados con los de Ku et al., ya que ella en sus resultados manifiesta que la ins- 1 se expresó hasta después de 11 días de cultivo.

La expresión de insulina y glucagón detectada mediante inmunocitoquímica, fue similar a la reportada por Jiang et al. (2002) y Chen et al., los cuales detectaron dicha expresión al día 20 de diferenciación, en tanto que el aumento de la expresión de insulina mediante citometría de flujo que observó Chen et al. fue del $18 \%$, semejante a la de este trabajo donde observamos un $15,4 \%$, con lo cual concluimos que los EBs están conformados por diferentes células pancreáticas tempranas. 
Referente al aumento en la complejidad de las células pancreáticas diferenciadas en comparación con la mESC, Chen et al. reportan resultados similares, por lo que postulamos que las ESC poseen características relacionadas a su indiferenciación como la baja complejidad y, conforme se especializan, aumenta dicha complejidad sin alterarse el tamaño celular.
Los resultados anteriores sugieren que es necesario continuar el estudio de protocolos de diferenciación para poder determinar el comportamiento de ESC sometidas a diferenciación, la obtención de células más especializadas y un posible uso terapéutico al implantar células diferenciadas en modelos animales.

VÁZQUEZ-ZAPIÉN, G. J.; SÁNCHEZ MONROY, V.; CHIRINO LÓPEZ, Y. I. \& MATA-MIRANDA, M. M. Morphological, genetic and protein characterization in the differentiation of embryonic stem cells to early pancreatic cells. Int. J. Morphol., 31(4):14211429,2013

SUMMARY: Due to the boom in regenerative medicine, Stem Cells (SC) represent a source of cell replacement to any tissue, we decided to undertake this research with the objective of differentiating mouse embryonic stem cells (mESC) to early pancreatic cells, developing their genetic and morphological characterization. Initially Mouse embryonic fibroblasts (MEF) were grown and arrested in their cell cycle with mitomycin, subsequently mouse embryonic SC (mESC) were expanded and subjected in to a pancreatic cell differentiation protocol of 21 days. During differentiation, morphology and the relative expression of sox-17, pdx-1, Ins-1 and Ins-2 genes were assessed, also the production of insulin and glucagon proteins was determinated by fluorescence microscopy and flow cytometry. Embryoid bodies (EBs) were obtained from mESC, with different morphological characteristics according to their differentiation, which expressed endodermal germ line genes (sox-17 y $p d x-1$ ) at days 0,11 and 17 of differentiation, an inductor gene of embryonic pancreas development (pdx-1) was detected at day 11 of differentiation. Pancreas genes (ins-1 e ins-2) were expressed at day 17 and 21 of differentiation. Finally the production of insulin and glucagon proteins was detected on the EBS at day 21 of differentiation. In conclusion, the mESC differentiation was achieved. The morphological analysis evidenced three-dimensional cell clusters corresponding to EBs. Analysis of the gene expression patterns in the differentiation process, cells initially showed genetic characteristics of endoderm and thereafter from day 17 of differentiation characteristics of early pancreatic cells which by day 21 of differentiation expressed insulin and glucagon proteins. The above results suggest the need to continue with the study of differentiation protocols to determine the ESC behavior under differentiation and their potential therapeutic use by implementing differentiated cells in animal models.

KEY WORDS: Stem cell; Stem cell differentiation; Differentiated cells; Embryoid bodies; Insulin-producers cells.

\section{REFERENCIAS BIBLIOGRÁFICAS}

Akincin, E.; Banga, A.; Greder, L. V.; Dutton, J. R. \& Slack, J. M. Reprogramming of pancreatic exocrine cells towards a beta (b) cell character using Pdx1, Ngn3 and MafA. Biochem. J., 442(3):539-50, 2012.

Baetge, E. E. Production of beta-cells from human embryonic stem cells. Diabetes Obes. Metab., 10(Suppl. 4):186-94, 2008.

Chen, C.; Chai, J.; Singh, L.; Kuo, C. Y.; Jin, L.; Feng, T.; Marzano, S.; Galeni, S.; Zhang, N.; Iacovino, M.; Qin, L.; Hara, M.; Stein, R.; Bromberg, J. S.; Kyba, M. \& Ku, H. T. Characterization of an in vitro differentiation assay for pancreatic-like cell development from murine embryonic stem cells: detailed gene expression analysis. Assay Drug Dev. Technol., 9(4):403-19, 2011.

Deltour, L.; Leduque, P.; Blume, N.; Madsen, O.; Dubois, P.; Jami, J. \& Bucchini, D. Differential expression of the two nonallelic proinsulin genes in the developing mouse embryo. Proc. Natl. Acad. Sci. USA, 90(2):527-31, 1993.

Evans, M. J. \& Kaufman, M. H. Establishment in culture of pluripotential cells from mouse embryos. Nature, 292(5819):154-6, 1981.
Expert Committee on the Diagnosis and Classification of Diabetes Mellitus. Report of the expert committee on the diagnosis and classification of diabetes mellitus. Diabetes Care, 26(Suppl. 1):S5-20, 2003.

Fomina-Yadlin, D.; Kubicek, S.; Vetere, A.; He, K. H.; Schreiber, S. L. \& Wagner, B. K. GW8510 increases insulin expression in pancreatic alpha cells through activation of p53 transcriptional activity. PLoS One, 7(1):e28808, 2012.

Giraldo, J.; Madero, C.; Ávila, M.; Cuneo, S.; López, C. \& Aparicio, A. Articulo de Revisión Celulas Madre. Rev. Colomb. Obst. Gin., 54(2):87-95, 2003.

Gu, G.; Dabauskaite, J. \& Melton, D. A. Direct evidence for the pancreatic lineage: NGN3+ cells are islet progenitors and distintic from duct progenitor. Development, 129(10):244757,2002

Hui, H. \& Perfettu, R. Pancreas duodenum homeobox-1 regulates pancreas development during embryogenesis an islet cell function in adulthood. Eur. J. Endocrinol., 146(2):129-41, 2002. 
Itskovitz-Eldor, J.; Schuldiner, M.; Karsenti, D.; Eden, A.; Yanuka, O.; Amit, M.; Soreq, H. \& Benvenisty, N. Differentiation of human embryonic stem cells into embryoid bodies compromising the three embryonic germ layers. Mol. Med., 6(2):88-95, 2000

Jang, Y. Y. \& Sharkis, S. J. Fetal to adult stem cell transition: knocking Sox17 off. Cell, 130(3):403-4, 2007.

Jiang, W.; Shi, Y.; Zhao, D.; Chen, S.; Yong, J.; Zhang, J.; Qing, T.; Sun, X.; Zhang, P.; Ding, M.; Li, D. \& Deng, H. In vitro derivation of functional insulin-producing cells from human embryonic stem cells. Cell Res., 17(4):333-44, 2007.

Kanai-Azuma, M.; Kanai, Y.; Gad, J. M.; Tajima, Y.; Taya, C.; Kurohmaru, M.; Sanai, Y.; Yonekawa, H.; Yazaki, K.; Tam, P. P. \& Hayashi, Y. Depletion of definitive gut endoderm in Sox17-null mutant mice. Development, 129(10):2367-79, 2002.

Kaneto, H.; Miyatsuka, T.; Kawamori, D. \& Matsuoka, T. A. Pleitropic roles of PDX-1 in the pancreas. Rev. Diabet. Stud., 4(4):209-25, 2007.

Ku, T.; Zhang, N.; Kubo, A.; O'Connor, R.; Mao, M.; Keller, G. \& Bromberg, J. S. Commiting Embryonic Stem cells to Early Endocrine Pancreas in vitro. Stem Cells, 22(7):1205-17, 2004.

Leahy, A.; Xiong, J. W.; Kuhnert, F. \& Stuhlmann, H. Use of developmental markers genes to define temporal and spatial patterns of differentiation during embryoid formation. J. Exp. Zool., 284(1):67-81, 1999.

Livak, K. J. \& Schmittgen, T. D. Analysis of relative gene expression data using real-time quantitative PCR and the 2(Delta Delta C(T)) Method. Methods, 25(4):402-8, 2001.

Niakan, K.K.; Ji, H.; Maehr, R.; Vokes, S. A.; Rodolfa, K. T.; Sherwood, R. I.; Yamaki, M.; Dimos, J. T.; Chen, A. E.; Melton, D. A.; McMahon, A. P. \& Eggan, K. Sox 17 promotes differentiation in mouse embryonic stem cells by directly regulating extra embryonic gene expression and indirectly antagonizing self-renewal. Genes Dev., 24(3):312-26, 2010.

Prósper, F.; Gavira, J.; Herreros, J.; Rabago, G.; Luquin, R.; Moreno-Montañes, J.; Robles, J. E. \& Redondo, P. Trasplante celular y terapia regenerativa con células madre. An. Sist. Sanit. Navar., 29(2):219-34, 2006.

Spradling, A.; Drummond-Barbosa, B. D. \& Kai, T. Stem cells find their niche. Nature, 414(6859):98-104, 2001.

Voog, J. \& Jones, D. L. Stem cells and the niche: a dynamic duo. Cell Stem Cell, 6(2):103-15, 2010

Walker, M. R.; Patel, K. K. \& Stappenbeck, T. S. The stem cell niche. J. Pathol., 217(2):169-80, 2009.
Wong, R. S. Extrinsinc factors involved in the diferentiation of stem cells into insulin producing cells. Exp. Diabetes Res., 2011:406182, 2011.

\section{Dirección para Correspondencia: \\ Gustavo Jesús Vázquez Zapién \\ Subsección de Investigación, Escuela Médico Militar \\ Universidad del Ejército y Fuerza Aérea \\ Col. Lomas de San Isidro, Miguel Hidalgo \\ C.P. 11620, México DF \\ MÉXICO}

Email: gus1202@hotmail.com

Recibido: 07-08-2013

Aceptado: 11-11-2013 